\title{
DETERMINAÇÃO ESPECTROFOTOMÉTRICA DE CEFALEXINA EM FORMULAÇÕES FARMACÊUTICAS EXPLORANDO A SUA REAÇÃO DE TRANSFERÊNCIA DE CARGA COM A QUINALIZARINA
}

\author{
Carlos Eduardo R. de Paula, Vanessa G. K. Almeida e Ricardo J. Cassella* \\ Departamento de Química Analítica, Universidade Federal Fluminense, Outeiro São João Batista, s/n, 24020-141 Niterói - RJ, Brasil.
}

Recebido em 16/9/09; aceito em 8/12/09; publicado na web em 25/3/10

\begin{abstract}
SPECTROPHOTOMETRIC DETERMINATION OF CEPHALEXIN IN PHARMACEUTICAL FORMULATIONS EXPLORING ITS CHARGE TRANSFER REACTION WITH QUINALIZARIN. This work proposes a new simple and fast spectrophotometric method for cephalexin determination in pharmaceutical formulations. The method is based on the charge transfer reaction between cephalexin and quinalizarin in dimethylsulfoxide medium. Several analytical parameters related to the system were optimized and the reaction was characterized in terms of stoichiometry. Also, association constant and apparent molar absorptivity of the product were determined. The method presented a limit of detection of $0.46 \mathrm{mg} \mathrm{L}^{-1}$ and a quantification limit of $1.5 \mathrm{mg} \mathrm{L}^{-1}$. It was successfully applied in the determination of cephalexin in two samples of commercial pharmaceutical formulations.
\end{abstract}

Keywords: cephalexin; charge transfer reaction; spectrophotometry.

\section{INTRODUÇÃO}

A primeira fonte das cefalosporinas, Cephalosporium acremonium, foi isolada em 1948 a partir do micro-organismo denominado Brotzu do mar, em uma localidade próxima a uma saída de esgoto na costa da Sardenha, Itália. Foi constatado que os filtrados não tratados de cultura destes micro-organismos inibiam in vitro o crescimento de Staphilococcus aureus. Posteriormente, verificou-se que os líquidos de culturas nos quais o fungo da Sardenha era cultivado continham três antibióticos distintos, que foram denominados inicialmente de cefalosporina $\mathrm{P}, \mathrm{N}$ e C. Com o isolamento do núcleo ativo da cefalosporina $\mathrm{C}$, o ácido 7-aminocefalosporânico, e com o acréscimo de cadeias laterais, foi possível produzir substâncias semissintéticas com uma atividade antibacteriana muito maior do que a substância original. A partir desta constatação foram produzidas as cefalosporinas de primeira geração, entre estas a cefalexina (ácido 7-(D-2-amino-2-fenilacetamido)-3metil-8-oxo-5-tia-1-azabiciclo [4.2.0]oct-2-eno-2-carboxílico), um antibiótico largamente utilizado na medicina humana para o combate de diversos tipos de infecções. A cefalexina (Figura 1) é extensamente comercializada no Brasil, uma vez que está presente em diversas formulações farmacêuticas de diferentes fabricantes. ${ }^{1}$



Figura 1. Estrutura química da cefalexina

No Brasil, atualmente, a automedicação constitui-se em um grave problema de saúde pública. Os antibióticos aparecem em segundo lugar entre os medicamentos mais utilizados pela população, sendo superados apenas pelos analgésicos. No caso dos antibióticos, o seu uso exagerado, entre outros fatores, pode levar ao aumento da resis-

\footnotetext{
*e-mail: cassella@vm.uff.br
}

tência bacteriana, tornando o medicamento cada vez mais ineficaz no tratamento da infecção. ${ }^{2}$ Neste contexto, o controle rigoroso das quantidades administradas aos pacientes pode ser considerado um assunto de importância social e econômica. Sem dúvida alguma, um dos aspectos importantes deste processo diz respeito ao controle das quantidades de princípios ativos presentes em medicamentos comerciais, o que exige o desenvolvimento de metodologias analíticas rápidas, simples, baratas e confiáveis.

No caso da cefalexina, o método oficial recomendado para sua determinação em medicamentos é aquele preconizado pelas farmacopeias americana ${ }^{3}$ e britânica. ${ }^{4}$ Este método baseia-se no emprego da técnica de cromatografia a líquido de alta eficiência com detecção espectrofotométrica, na região do UV. Por sua vez, a literatura científica relata o desenvolvimento de outros métodos analíticos para este fim em que outras técnicas analíticas são empregadas tais como a espectrofluorimetria, ${ }^{5}$ a quimioluminescência,${ }^{6,7}$, a eletroforese capilar ${ }^{8}$ e a espectrofotometria. ${ }^{9-14}$ Ainda, outros vários métodos baseados na cromatografia a líquido de alta eficiência já foram relatados para este fim. ${ }^{15-17}$ Entretanto, estes métodos cromatográficos são caracterizados pela baixa produtividade e pelo alto custo da instrumentação, quando comparados com os métodos espectrofotométricos.

Apesar de sua simplicidade, a espectrofotometria na região do visível requer a escolha de reações adequadas, visto que a formação do produto colorido é uma etapa fundamental para o sucesso da metodologia. No caso da cefalexina, a principal característica dos métodos espectrofotométricos já desenvolvidos para sua determinação é a baixa velocidade analítica, uma vez que tempos de reação longos (30 a 60 min) são normalmente requeridos para o sistema atingir o equilíbrio e, em consequência, a sensibilidade necessária para a análise.

Os métodos espectrofotométricos para determinação de cefalexina podem ser classificados de acordo com a reação envolvida. Alguns trabalhos exploram a reação da cefalexina com espécies metálicas e outros, a hidrólise alcalina da droga e a reação de seus produtos de degradação com reagentes específicos. Agbaba et al. ${ }^{9}$ e Issopoulos ${ }^{10}$ podem ser citados para o caso das reações de complexação, já que empregaram reações de complexação da cefalexina com $\mathrm{Ni}(\mathrm{II})$ e $\mathrm{Cu}(\mathrm{II})$, respectivamente, para a determinação deste fármaco em formulações farmacêuticas.

Por sua vez, Mohamed ${ }^{11}$ e Al-Momani ${ }^{12}$ determinaram a cefalexina após a sua hidrólise em meio alcalino. No primeiro caso, os autores ex- 
ploraram a reação do íon sulfeto, obtido na hidrólise, $\operatorname{com} p$-aminofenol, que produziu um composto de coloração violeta com forte absorção em $550 \mathrm{~nm}$. No caso de Al-Momani, ${ }^{12}$ o sulfeto formado foi oxidado pelo iodo, sendo que o monitoramento da reação foi realizado em $460 \mathrm{~nm}$.

Reagentes comumente utilizados em reações de transferência de carga também já foram empregados para a determinação de cefalexina. Saleh et al..$^{13}$ desenvolveram um método que se baseia na reação de transferência de carga entre a cefalexina (doador de elétrons) e os reagentes 2,3-dicloro-5,6-diciano-p-benzoquinona (DDQ) e 7,7,8,8-tetraciano-quinona-di-metano (TCNQ), típicos aceptores de elétrons. Em outro estudo, Saleh e Askal ${ }^{14}$ desenvolveram uma metodologia para a determinação de cefalexina com o ácido $p$-cloranílico ( $p$-CA), também um reagente aceptor de elétrons. Neste trabalho, os autores verificaram a formação de um ânion-radicalar, derivado do p-CA, que apresentou forte absorção em $520 \mathrm{~nm}$.

As reações de transferência de carga vêm sendo empregadas há alguns anos para a determinação espectrofotométrica de diferentes princípios ativos presentes em medicamentos. ${ }^{18-21}$ Estes métodos exploram o caráter básico de algumas drogas que, devido a esta característica, são excelentes doadoras de elétrons, principalmente de elétrons n. Por sua vez, a fim de completar a reação de transferência de carga, reagentes aceptores de elétrons são utilizados tais como o DDQ, o TCNQ e o $p$-CA, já citados anteriormente. A quinalizarina jamais foi utilizada para este propósito anteriormente. Assim, o objetivo deste trabalho foi desenvolver uma metodologia para determinação de cefalexina em formulações farmacêuticas explorando a sua reação de transferência de carga com a quinalizarina. Adicionalmente, estudos foram realizados com o intuito de caracterizar a reação sob o ponto de vista da estequiometria e do mecanismo.

\section{PARTE EXPERIMENTAL}

\section{Equipamentos}

As medições de absorvância foram efetuadas com um espectrofotômetro marca Femto, modelo 800 XI, empregando sempre uma resolução nominal de $1 \mathrm{~nm}$. Uma cubeta de quartzo de $10 \mathrm{~mm}$ de caminho ótico (Hellma, Mullheim, Alemanha) foi utilizada em todas as medições. Tanto o controle do equipamento como a aquisição e o tratamento dos dados obtidos foram realizados com o auxílio de um microcomputador equipado com um processador Pentium IV.

Em todas as etapas do trabalho foi utilizada uma balança analítica And (Tóquio, Japão), modelo GR-202 com precisão de 0,01 mg.

\section{Reagentes e soluções}

Todos os solventes utilizados (dimetilsulfóxido, etanol, metanol e acetonitrila) foram de grau HPLC e fornecidos pela Tedia Brazil (São Paulo, Brasil). A água empregada em todas as etapas do trabalho foi obtida a partir de um sistema de ultrapurificação Simplicity Milli-Q (Millipore, Saint Quentin Yvelines, França).

A solução estoque de $500 \mathrm{mg} \mathrm{L}^{-1}$ de quinalizarina $(1,2,3,4$ tetra-hidroxiantraquinona) foi preparada a partir da dissolução de $50 \mathrm{mg}$ do reagente (Acros Organics, St. Louis, EUA) em $100 \mathrm{~mL}$ de dimetilsulfóxido. Todas as soluções de quinalizarina empregadas foram preparadas imediatamente antes de sua utilização.

A solução estoque padrão de cefalexina de $1000 \mathrm{mg} \mathrm{L}^{-1}$ foi preparada pela dissolução de $10 \mathrm{mg}$ de cefalexina padrão (Genix, Anápolis, Brasil), de grau farmacêutico, em cerca de $5 \mathrm{~mL}$ de água. A fim de garantir a completa solubilização do reagente, a mistura foi agitada em ultrassom por $10 \mathrm{~min}$. Após a dissolução total da cefalexina, a solução obtida foi transferida para um balão volumétrico de $10 \mathrm{~mL}$ e o volume foi completado com água.

\section{Construção da curva analítica}

Alíquotas da solução estoque de cefalexina foram transferidas, separadamente, para balões volumétricos de $25 \mathrm{~mL}$. Em cada balão foram adicionados $2,5 \mathrm{~mL}$ da solução estoque de quinalizarina (500 $\mathrm{mg} \mathrm{L}^{-1}$ ). Em seguida, a mistura foi agitada, a fim de promover a reação entre a cefalexina e a quinalizarina, e o volume foi completado com dimetilsulfóxido. As absorvâncias das soluções obtidas foram medidas em $579 \mathrm{~nm}$ contra um branco contendo a mesma quantidade de quinalizarina em dimetilsulfóxido.

\section{Preparação das amostras}

As amostras analisadas foram adquiridas em drogarias localizadas no município de Niterói, Estado do Rio de Janeiro. Cinco comprimidos de cada amostra foram pesados separadamente (cerca de 620 mg cada um) e macerados empregando-se gral e pistilo de porcelana. Uma massa de $50 \mathrm{mg}$ da amostra macerada foi pesada e dispersada em $25 \mathrm{~mL}$ de água. A suspensão obtida foi sonicada por $10 \mathrm{~min}$ e em seguida filtrada, utilizando-se filtros de membrana de PTFE com diâmetro de poro de $0,2 \mu \mathrm{m}$. Uma alíquota de $250 \mu \mathrm{L}$ da solução obtida foi transferida para um balão volumétrico de $25 \mathrm{~mL}, 2,5 \mathrm{~mL}$ da solução estoque de quinalizarina foram adicionados e o volume foi completado até a marca com dimetilsulfóxido. A absorvância foi medida em $579 \mathrm{~nm}$ contra uma solução-branco contendo apenas quinalizarina em dimetilsulfóxido.

O mesmo procedimento foi adotado nos ensaios de recuperação. Entretanto, neste caso, apenas um comprimido foi macerado junto com quantidades conhecidas (100 e $200 \mathrm{mg}$ ) de cefalexina padrão. $\mathrm{O}$ restante do procedimento foi idêntico ao descrito anteriormente para a análise das amostras não fortificadas.

\section{RESULTADOS E DISCUSSÃO}

O desenvolvimento da metodologia para determinação espectrofotométrica de cefalexina em formulações farmacêuticas, empregando a reação de transferência de carga do analito com a quinalizarina, foi realizado em três etapas. Na primeira etapa, as condições experimentais (efeito da natureza do solvente, influência da concentração do reagente e tempo necessário para completar a reação) foram otimizadas, para obtenção de máxima sensibilidade analítica, empregando-se uma estratégia univariada. Posteriormente, a reação de transferência de carga entre a cefalexina e a quinalizarina foi avaliada no que diz respeito à estequiometria, empregando-se o método de Job. ${ }^{22}$ Nesta etapa também foram determinadas a constante de associação e a absortividade molar aparente do composto colorido formado. Finalmente, na última etapa do trabalho, o método desenvolvido foi aplicado na determinação de cefalexina em quatro amostras de medicamentos comerciais a fim de testar a sua aplicabilidade.

\section{Efeito da natureza do solvente}

O solvente possui um papel importante em algumas reações de transferência de carga, uma vez que ele deve ser capaz de estabilizar o ânion radicalar formado após a reação de transferência de carga. Adicionalmente, de acordo com a literatura, ${ }^{23,24}$ os solventes polares facilitam a transferência total de carga, fazendo com que o ânion radicalar formado seja a espécie cromogênica predominante no meio. Neste estudo foram testados os seguintes solventes: metanol, etanol, dimetilsulfóxido (DMSO) e acetonitrila. A água não foi testada devido à baixa solubilidade da quinalizarina neste solvente. Os resultados obtidos neste experimento podem ser vistos na Figura 2. 


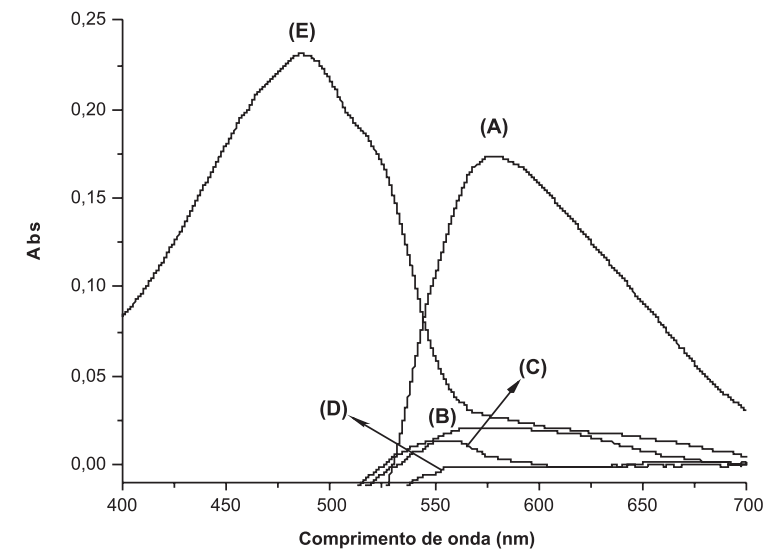

Figura 2. Espectros na região do visível de soluções de quinalizarina (E) e da mistura cefalexina-quinalizarina (A-D) em diferentes solventes: $(A)$ dimetilsulfóxido, (B) acetonitrila, (C) metanol, e (D) etanol. Em todos os casos, a concentração de cefalexina foi igual a $25 \mathrm{mg} \mathrm{L}^{-1}$ e a concentração de quinalizarina foi igual a $50 \mathrm{mg} \mathrm{L}^{-1}$, exceto para o espectro (E) em que a concentração de quinalizarina foi igual a $10 \mathrm{mg} \mathrm{L}^{-1}$

Como pode ser verificado, um sinal de absorvância máximo foi obtido quando o dimetilsulfóxido foi empregado como solvente e, deste modo, este solvente foi escolhido para o método. Praticamente nenhum sinal analítico foi observado quando os outros solventes foram testados. Este fenômeno pode ser explicado pela alta constante dielétrica do DMSO, que o faz mais eficiente do que os outros solventes testados para estabilização da estrutura carregada (radicalânion) formada a partir da dissociação do complexo de transferência de carga cefalexina-quinalizarina.

Na Figura 2 também pode ser visto o espectro da quinalizarina, em DMSO. Pode-se observar que o máximo da banda de absorção da quinalizarina neste solvente ocorreu em $486 \mathrm{~nm}$, enquanto que o máximo da banda de absorção do radical-ânion foi observado em 579 $\mathrm{nm}$. Esta grande diferença (93 nm) entre os máximos de absorção do reagente e do produto formado possibilitou a utilização desta reação para fins analíticos, uma vez que, nestas condições, apenas uma leve sobreposição entre os espectros pode ser verificada, possibilitando a medição da absorvância do produto com mínima interferência devido ao excesso de reagente adicionado ao meio. É importante destacar que as soluções de cefalexina são incolores e, portanto, não apresentam absorção de radiação na região do visível, em quaisquer dos solventes testados.

\section{Efeito da concentração do reagente}

A fim de obter máxima sensibilidade analítica, a influência da concentração final de quinalizarina no meio reacional sobre o sinal de absorvância foi avaliada. Neste experimento, fixou-se a concentração de cefalexina em $25 \mathrm{mg} \mathrm{L}^{-1} \mathrm{e}$ a de quinalizarina foi variada na faixa de 2,5 a $100 \mathrm{mg} \mathrm{L}^{-1}$. Os resultados obtidos estão mostrados na Figura 3. Um grande aumento do sinal analítico foi observado com o aumento da concentração do reagente até $50 \mathrm{mg} \mathrm{L}^{-1}$. A partir deste ponto, observa-se leve aumento do sinal, demonstrando que toda a cefalexina adicionada já havia sido consumida na reação com a quinalizarina. É importante ressaltar que os valores de absorvância obtidos com as soluções branco (contendo apenas quinalizarina em cada concentração avaliada) também aumentaram com o aumento da concentração do reagente. Assim, com o intuito de obter maior sensibilidade analítica e trabalhar em condições em que a interferência, devido ao excesso de reagente adicionado, fosse minimizada, selecionou-se a concentração de $50 \mathrm{mg} \mathrm{L}^{-1}$ de quinalizarina.

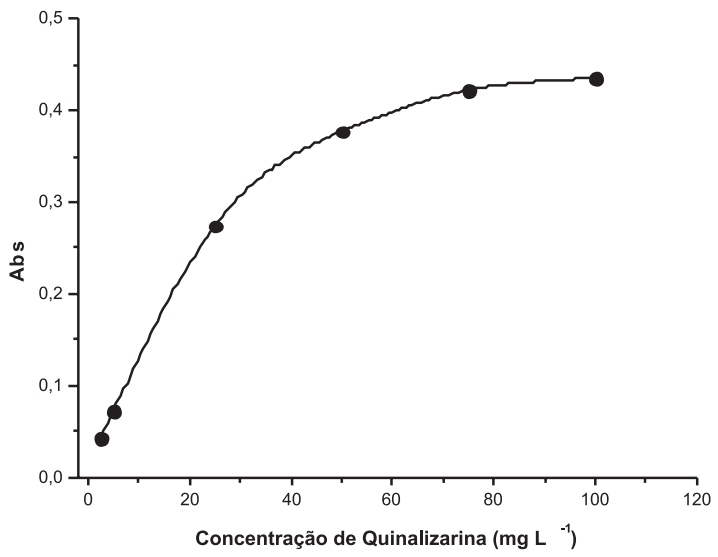

Figura 3. Efeito da concentração de quinalizarina na absorvância das soluções de cefalexina-quinalizarina. Concentração de cefalexina $25 \mathrm{mg} \mathrm{L}^{-1}$

\section{Efeito do tempo de reação}

A avaliação do tempo de reação foi realizada pelo monitoramento do sinal analítico, em $579 \mathrm{~nm}$, de uma solução contendo $25 \mathrm{mg} \mathrm{L}^{-1}$ de cefalexina e $50 \mathrm{mg} \mathrm{L}^{-1}$ de quinalizarina em meio de DMSO, durante 180 min. Os sinais de absorvância permaneceram estáveis durante o experimento, sendo observada uma variação sempre menor do que $2 \%$, indicando que o produto da reação entre a quinalizarina e a cefalexina se forma instantaneamente e não sofre degradação por pelo menos $180 \mathrm{~min}$. Vale ressaltar que este experimento foi realizado à temperatura ambiente $\left(24 \pm 1{ }^{\circ} \mathrm{C}\right)$. Considerando que o tempo decorrido entre o preparo da amostra e o início das medições do sinal analítico é sempre inferior a 180 min, pode-se verificar que não há variação da absorvância das soluções com o tempo.

\section{Avaliação da estequiometria da reação}

A estequiometria da reação de transferência de carga entre a quinalizarina e a cefalexina foi determinada com base nos resultados obtidos empregando-se o método das variações contínuas, proposto por Job. ${ }^{22}$ Neste experimento, a relação molar entre os reagentes na solução final foi variada, empregando-se alíquotas com volumes variáveis de soluções $1,0 \times 10^{-3} \mathrm{~mol} \mathrm{~L}^{-1}$ de ambos. Os resultados obtidos deram origem ao gráfico de razão molar contra absorvância, mostrado na Figura 4. Como pode ser visto, máxima absorvância foi obtida quando a razão $[\mathrm{CEF}] /([\mathrm{CEF}]+[\mathrm{QLZ}])$ foi igual a 0,32 . Neste caso, a proporção [QLZ]/([CEF] + [QLZ]) foi então igual a 0,68 , indicando que a reação entre a cefalexina e a quinalizarina ocorre na proporção de 1:2.

O resultado obtido neste experimento é compatível com o mecanismo proposto para a reação (Esquema 1), no qual um elétron de cada átomo de nitrogênio (dos grupamentos amino) da molécula de cefalexina é transferido para o centro deficiente de carga da quinalizarina, com a formação de um complexo de transferência de carga na proporção de uma molécula de cefalexina para duas moléculas de quinalizarina. De acordo com Ayad et al.,${ }^{25} \mathrm{em}$ solventes muito polares, como é o caso do DMSO, pode ocorrer a dissociação do complexo com a formação de um ânion radicalar (espécie absorvente) como resultado da transferência total da carga do doador para o aceptor que seriam, no presente estudo, a cefalexina e a quinalizarina, respectivamente. Mecanismo similar a este já foi proposto em outros estudos de reações de transferência de carga da cefalexina com outros reagentes aceptores de elétrons tais como o TCNQ e o $p$-CA ${ }^{13,14}$ e em outros sistemas envolvendo outros analitos..$^{18,26}$ 


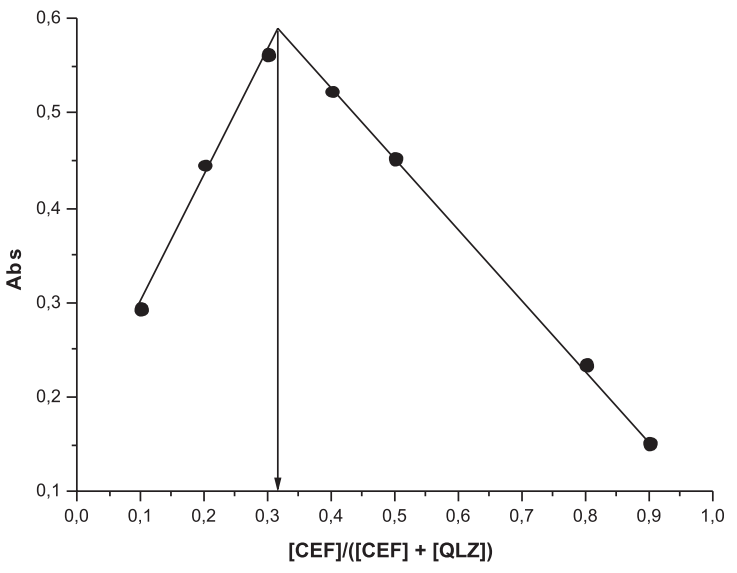

Figura 4. Aplicação do método de Job para reação entre cefalexina e quinalizarina
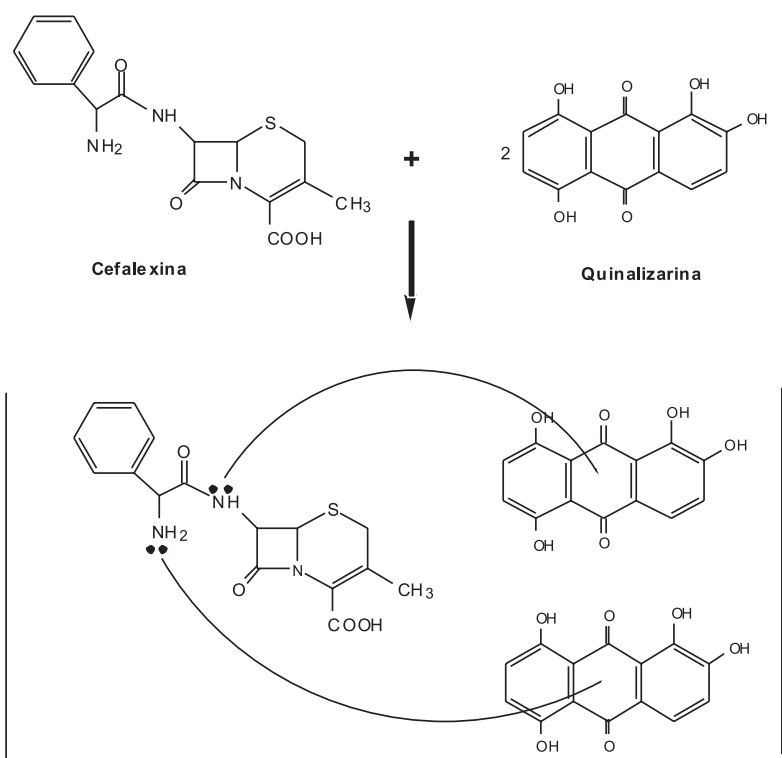

Comple xo Cefalex ina-Quina lizarina

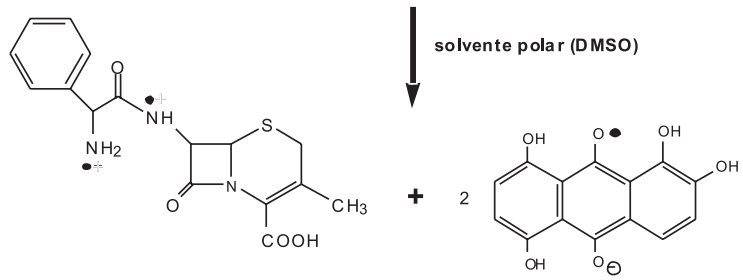
Ânion radical ar de rivado da quinalizarina
Espécie absorvente

Esquema 1. Possível mecanismo de formação do ânion radicalar derivado da quinalizarina, após reação com a cefalexina

Deve-se considerar ainda que o átomo de nitrogênio presente no anel é bem menos básico do que os outros nitrogênios da molécula de cefalexina, provavelmente devido à baixa disponibilidade dos seus elétrons livres como consequência do impedimento estérico observado nesta situação. Assim, eles não são capazes de reagir com a quinalizarina.

\section{Cálculo da absortividade molar aparente e da constante de associação}

Alguns autores sustentam que os complexos formados nas reações de transferência de carga podem ser dissociados na presença de solventes polares, como resultado da transferência total da carga do doador para o aceptor. ${ }^{23,24}$ Neste caso, ocorre a formação de um ânion radicalar que, geralmente, é a espécie absorvente nos métodos espectrofotométricos desenvolvidos com base nestas reações. Deste modo, alguns parâmetros importantes como constante de associação e absortividade molar aparente, relativos à reação e ao produto formado, podem ser determinados. Neste estudo, estes parâmetros foram encontrados usando-se a equação proposta por Ross e Labes, ${ }^{27}$, representada pela Equação 1. O experimento foi realizado à temperatura ambiente $\left(24 \pm 1{ }^{\circ} \mathrm{C}\right)$.

$\frac{[\mathrm{QLZ}][\mathrm{CEF}]}{[\mathrm{QLZ}]+[\mathrm{CEF}]} \times \frac{1}{\mathrm{~A}}=\frac{1}{\mathrm{~K} \cdot \varepsilon} \times \frac{1}{[\mathrm{QLZ}]+[\mathrm{CEF}]}+\frac{1}{\varepsilon}$

onde [CEF] e [QLZ] são as concentrações de cefalexina e quinalizarina, respectivamente. $A$ e são a absorvância e absortividade molar aparente do complexo em 579 nm e K é a constante de associação do complexo.

A aplicação da equação de Ross e Labes requer a construção de um gráfico de 1/([QLZ] + [CEF]) contra ([QLZ] [CEF]/[QLZ] + $[\mathrm{CEF}]) \times$ 1/A (Figura 5). A partir dos coeficientes linear e angular obtidos pode-se calcular a absortividade molar aparente e a constante de associação, respectivamente. Os valores obtidos para o sistema cefalexina-quinalizarina em DMSO foram 4,31 x $10^{3} \mathrm{~L} \mathrm{~mol}^{-1} \mathrm{~cm}^{-1}$ para absortividade molar aparente e 4,23 x $10^{2}$ para a constante de associação. No caso da constante de associação, deve-se levar em consideração que a constante obtida representa a constante média para as reações de transferência de carga com os elétrons livres dos dois nitrogênios envolvidos no processo.

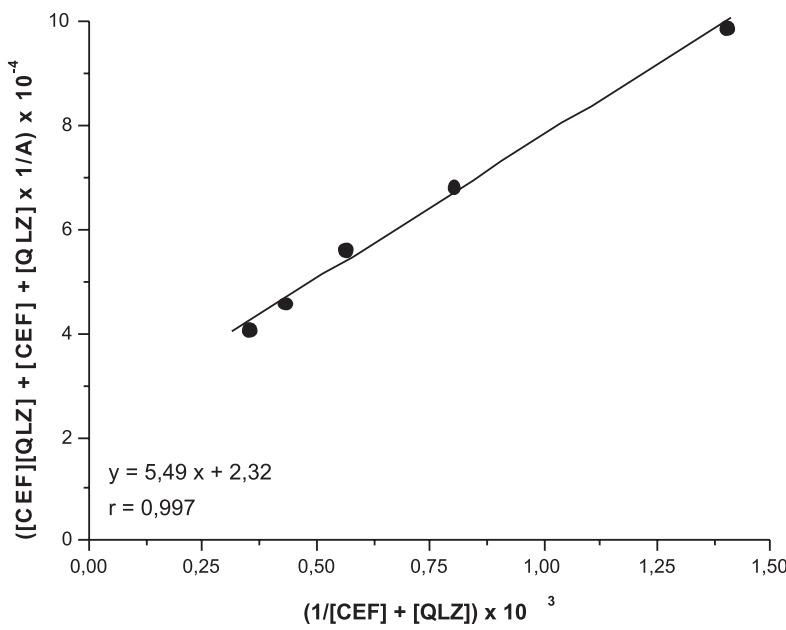

Figura 5. Aplicação da equação Ross e Labes para determinação da absortividade molar aparente e constante de associação do presente sistema

\section{Estudo de interferentes}

Na avaliação de possíveis interferentes foram testados o tensoativo dodecilsulfato de sódio (SDS) e o corante amarelo crepúsculo. Estas substâncias normalmente são encontradas nas formulações dos medicamentos contendo cefalexina. As outras substâncias também presentes na composição do excipiente se mostraram pouco solúveis em água, sendo retidas na etapa de filtração durante a preparação da amostra.

Mantendo a concentração de $25 \mathrm{mg} \mathrm{L}^{-1}$ de cefalexina e $50 \mathrm{mg} \mathrm{L}^{-1}$ de quinalizarina, os resultados obtidos indicaram que o SDS poderia causar interferência no sinal analítico quando em concentração superior a $250 \mathrm{mg} \mathrm{L}^{-1}$. Entretanto, devido à diluição das amostras, aliado às baixas concentrações de SDS normalmente encontrada nas mesmas 
(algo entre 0,5 e 1\%), o composto não é um interferente para o método. No caso do amarelo crepúsculo, os resultados obtidos demonstraram que não há alteração significativa (superior a 5\%) do sinal analítico até $100 \mathrm{mg} \mathrm{L}^{-1}$, concentração superior àquelas regularmente encontradas em medicamentos comerciais.

\section{Características analíticas do método}

Após a otimização das variáveis envolvidas na reação, curvas analíticas foram obtidas na faixa de 4 a $30 \mathrm{mg} \mathrm{L}^{-1}$, com uma equação típica igual $\mathrm{A}=0,0227[\mathrm{CEF}]+0,002$, onde A representa a absorvância e CEF é a concentração de cefalexina em $\mathrm{mg} \mathrm{L}^{-1}$. Uma correlação satisfatória entre os valores de absorvância e a concentração de cefalexina foi observada, uma vez que coeficientes de determinação sempre superiores a 0,99 foram obtidos. Nas condições otimizadas, as concentrações referentes aos limites de detecção (3s) e quantificação (10s) foram iguais 0,46 e $1,54 \mathrm{mg} \mathrm{L}^{-1}$, respectivamente. O desvio padrão relativo foi igual a 3,9\% para uma solução de $4 \mathrm{mg} \mathrm{L}^{-1} \mathrm{CEF}$. Vale ressaltar que este parâmetro foi avaliado pela medição de dez soluções independentes de CEF.

\section{APLICAÇÃO DA METODOLOGIA}

A metodologia desenvolvida foi aplicada na determinação de cefalexina em quatro amostras de medicamentos vendidos no Brasil. Para todas as amostras, os valores indicados pelos fabricantes eram de $530 \mathrm{mg}$ de cefalexina mono-hidratada por comprimido. Os resultados obtidos utilizando a metodologia otimizada foram comparados com os valores declarados pelos fabricantes e são apresentados na Tabela 1. Como pode ser visto, nas quatro amostras analisadas foram encontradas quantidades de cefalexina mono-hidratada superiores àquelas declaradas nas bulas. Entretanto, deve-se considerar que estes valores estão dentro das regulamentações indicadas pela Farmacopéia Brasileira, ${ }^{28}$ que determina que, no caso de comprimidos, o conteúdo analisado deve estar entre 85 e $115 \%$ do valor declarado.

Tabela 1. Resultados obtidos na determinação de cefalexina mono-hidratada em formulações farmacêuticas comerciais. Tais resultados são apresentados como a média de três determinações independentes \pm desvio padrão

\begin{tabular}{lcc}
\hline Amostra & Método proposto $(\mathrm{mg})$ & Diferença* $(\%)$ \\
\hline A & $585 \pm 5$ & $+10,4$ \\
B & $572 \pm 2$ & $+7,9$ \\
C & $586 \pm 6$ & $+10,6$ \\
D & $587 \pm 3$ & $+10,8$ \\
\hline
\end{tabular}

*Diferença em relação ao valor declarado pelo fabricante.

Como os valores rotulados não podem ser tomados como parâmetro para atestar a exatidão da metodologia desenvolvida, esta foi verificada através da realização de ensaios de recuperação. Os resultados obtidos nestes ensaios de recuperação estão mostrados na Tabela 2. Neste ensaio, foram adicionados 100 e $200 \mathrm{mg}$ de cefalexina padrão a quantidades definidas de amostra, durante o processo de maceração. Posteriormente, as amostras fortificadas sofreram o mesmo tratamento dado às amostras não fortificadas e as concentrações de cefalexina foram determinadas pelo método desenvolvido antes e após a adição de cefalexina padrão. Os valores de recuperação obtidos situaram-se entre 92 e $105 \%$, indicando que procedimento desenvolvido é eficiente para determinação de cefalexina em medicamentos comerciais.

\section{CONCLUSÕES}

A metodologia desenvolvida neste trabalho pode ser considerada uma alternativa para a determinação de cefalexina em formulações
Tabela 2. Resultados obtidos no ensaio de recuperação para duas amostras de formulações farmacêuticas contendo cefalexina

\begin{tabular}{lccc}
\hline Amostra & $\begin{array}{c}\text { Massa de padrão } \\
\text { adicionada }(\mathrm{mg})\end{array}$ & $\begin{array}{c}\text { Massa recuperada } \\
(\mathrm{mg})\end{array}$ & $\begin{array}{c}\text { Recuperação } \\
(\%)\end{array}$ \\
\hline $\mathrm{A}$ & 107 & $105 \pm 4$ & 98 \\
& 212 & $195 \pm 2$ & 92 \\
$\mathrm{~B}$ & 101 & $106 \pm 1$ & 102 \\
& 205 & $217 \pm 5$ & 105 \\
$\mathrm{C}$ & 102 & $101 \pm 3$ & 99 \\
& 202 & $204 \pm 5$ & 101 \\
$\mathrm{D}$ & 100 & $97 \pm 3$ & 97 \\
\hline
\end{tabular}

farmacêuticas, uma vez que apresentou exatidão, baixo custo, rapidez, simplicidade e seletividade adequada para aplicação neste tipo de amostra. Ainda, devido a sua facilidade de operação, pode ser utilizado para o controle de qualidade de formulações contendo cefalexina.

De acordo com os resultados obtidos pode ser verificado que a reação de transferência de carga entre a cefalexina e a quinalizarina apresenta melhor rendimento em meio de dimetilsulfóxido, possivelmente devido à alta constante dielétrica deste solvente, que permite a formação e estabilização do um ânion radicalar da quinalizarina. Ainda, a reação ocorre de modo instantâneo, o que faz com que o método apresente alta produtividade, requisito fundamental para seu uso em sistema de rotina.

Do ponto de vista analítico, o método apresentou boa sensibilidade, podendo ser aplicado na faixa de concentrações de 4 a $30 \mathrm{mg}$ $\mathrm{L}^{-1}$ de cefalexina, que corresponde a concentrações molares da droga da ordem de $1,2 \times 10^{-5}$ a $8,6 \times 10^{-5} \mathrm{~mol} \mathrm{~L}^{-1}$.

\section{AGRADECIMENTOS}

Ao CNPq (Conselho Nacional Desenvolvimento Científico e Tecnológico) e à CAPES (Coordenação de Aperfeiçoamento de Pessoal de Nível Superior) pelas bolsas concedidas e pelo suporte financeiro.

\section{REFERÊNCIAS}

1. Hardaman, J. G.; Limbird, L. E.; Gilman, A. G.; Goodman and Gilman's - The Pharmacological basic of therapeutics, $9^{\mathrm{a}}$ ed., McGraw-Hill: New York, 1995.

2. Conselho Regional de Farmácia do Estado do Rio de Janeiro - Revista Riopharma 2005, 67, 26.

3. The United States Pharmacopeia - The National Formulary - USP 27; NF- 22, 2004, p. 198.

4. European Pharmacopeia; $4^{\text {th }}$ ed., 2002, p. 831.

5. Omar, M. A.; Abdelmageed, O. H.; Attia, T. Z.; Talanta 2009, 77, 1394.

6. Thongpoon, C.; Liawruangrath, B.; Liawruangrath, S.; Wheatley, R. A.; Townshend, A.; Anal. Chim. Acta 2005, 553, 123.

7. Sun Y.; Tang, Y.; Yao, H.; Zheng, X.; Talanta 2004, 64, 156.

8. Mrestania, Y.; Neuberta, R. H. H.; Hartl, A.; Wohlrab, J.; Anal. Chim. Acta 1997, 349, 207.

9. Agbaba, D.; Eric, S.; Karljikovic-Rajic, K.; Vladimirov, S.; ZivanovStakic, D.; Spectrosc. Lett. 1997, 30, 309.

10. Issopoulos, P.; J. Pharm. Biomed. Anal. 1988, 6, 97.

11. Mohamed, F.; Proceedings of Assiut University $1^{\text {st }}$ Pharmaceutical Science Conference 1988, 4-5, 1.

12. Al-Momani, I. F.; Anal. Lett. 2004, 37, 2099.

13. Saleh, G. A.; Askal, H. F.; Radwan, M. F.; Omar, M. A.; Talanta 2001, $54,1205$.

14. Saleh, G. A.; Askal, H. F.; Anal. Sci. 2003, 19, 281.

15. Oliveira, R. V.; De Pietro, A. C.; Cass, Q. B.; Talanta 2007, 71, 1233. 
16. Samanidou, V. F.; Hapeshi, E. A.; Papadoyannis, I. N.; J. Chromatogr. B 2003, 788, 147 .

17. Campins-Falcó, P.; Sevillano-Cabeza, A.; Gallo-Martinez, L.; BoschReig, F.; Monzó-Mansanet, I.; Mikrochim. Acta 1997, 126, 207.

18. Rahman, N.; Anwar, N.; Kashif, M.; Il Farmaco 2005, 60, 605.

19. Mostafa, S.; El-Sadek, M.; Alla, E. A.; J. Pharm. Biomed. Anal. 2002, 27, 133.

20. Arslan, M.; Duymus, H.; Spectrochim. Acta Part A 2007, 67, 573.

21. Mostafa, A. A.; Bebawy, L. I.; Refaat, H. H.; J. Pharm. Biomed. Anal. 2002, 27, 889 .
22. Job, P.; Ann. Chem. 1928, 9, 113.

23. Trommnosolarff, H. P.; J. Chem. Phys. 1972, 56, 5358.

24. Basavaiah, K.; Il Farmaco 2004, 59, 315.

25. Ayad, M. M.; Belal, S.; El-Adl, S. B.; Al-Kheir, A. A.; Analyst 1984, 109, 1417

26. Adikwu, M. U.; Ofokansi, K. C.; J. Pharm. Biomed. Anal. 1997, 16, 529

27. Ross, S. D.; Labes, M. M.; J. Am. Chem. Soc. 1957, 79, 76.

28. Farmacopéia Brasileira; IV Ed., parte II, 5º fascículo, 2003, p. 218. 